\title{
Association of Health Literacy and Numeracy with Interest in Research Participation
}

\author{
Sunil Kripalani, $M D, M S c^{1,2,3}$, William J. Heerman, $M D, M P H^{2,4}$, Niral J. Patel, $\mathrm{MPH}^{3}$, \\ Natalie Jackson, $\mathrm{MPH}^{4}$, Kathryn Goggins, $\mathrm{MPH}^{2,3}$, Russell L. Rothman, MD, MPP',2,3, \\ Vivian M. Yeh, $P h D^{3}$, Kenneth A. Wallston, $P h D^{2,5}$, Duane T. Smoot, $M D^{6}$, and \\ Consuelo H. Wilkins, MD, MSC $\beta^{, 7,8}$
}

\begin{abstract}
'Division of General Internal Medicine and Public Health, Department of Medicine, Vanderbilt University Medical Center, Nashville, TN, USA; ${ }^{2}$ Center for Effective Health Communication, Vanderbilt University Medical Center, Nashville, TN, USA; ${ }^{3}$ Center for Clinical Quality and Implementation Research, Vanderbilt University Medical Center, Nashville, TN, USA; ${ }^{2}$ Division of General Pediatrics, Monroe Carell Jr. Children's Hospital at Vanderbilt, Nashville, TN, USA; ${ }^{5}$ School of Nursing, Vanderbilt University, Nashville, TN, USA; ${ }^{6}$ Department of Internal Medicine, Meharry Medical College, Nashville, TN, USA; ${ }^{7}$ Meharry-Vanderbilt Alliance, Vanderbilt University Medical Center, Nashville, TN, USA; ${ }^{8}$ Division of Geriatrics, Department of Medicine, Vanderbilt University Medical Center, Nashville, TN, USA.
\end{abstract}

BACKGROUND: There is much attention to recruitment of diverse populations in research, but little is known about the influence of health literacy and numeracy skills. OBJECTIVE: To determine if health literacy and numeracy affect individuals' interest to participate in research studies.

DESIGN: Cross-sectional survey data were pooled from 3 large studies conducted in the Mid-South Clinical Data Research Network.

PARTICIPANTS: Adult patients enrolled in 1 of 3 MidSouth Clinical Data Research Network studies.

MAIN MEASURES: The survey domains included demographic items, the 3-item Brief Health Literacy Screen (range 3-15), and the 3-item Subjective Numeracy Scale (range 318). The outcome was a sum index measure of a 7 -item instrument (range 7-21) assessing individuals' interest in participating in different types of research, including research that involves taking surveys, giving a blood sample, participating via phone or internet, taking an investigational medication, meeting at a local community center or school, including family, or staying overnight at a hospital.

KEY RESULTS: Respondents $(N=15,973)$ were predominately women $(65.5 \%)$, White $(81.4 \%)$, and middle aged $(M=52.8$ years, $\mathrm{SD}=16.5) ; 32.4 \%$ previously participated in research. Self-reported health literacy was relatively high $(M=13.5$ out of $15, \mathrm{SD}=2.1)$, and subjective numeracy skills were somewhat lower $(M=14.3$ out of $18, \mathrm{SD}=3.6)$. After adjustment for age, gender, race, income, education, and other characteristics, lower health literacy and numeracy skills were each independently associated with less interest in research participation ( $p<0.001$ for each). Prior research participation was associated with greater interest in future research participation $(p<0.001)$.

CONCLUSIONS: After adjustment for factors known to be predictive of interest, individuals with lower health literacy or numeracy scores were less interested in participating in research. Additional work is needed to elucidate reasons for this finding and to determine strategies to engage these populations.

Received February 9, 2018

Revised July 3, 2018

Accepted November 20, 2018

Published online January 25, 2019
KEY WORDS: health literacy; health numeracy; survey research.

J Gen Intern Med 34(4):544-51

DOI: $10.1007 / \mathrm{s} 11606-018-4766-2$

(c) Society of General Internal Medicine 2019

\section{INTRODUCTION}

Medical research is crucial to developing new and effective health care interventions. However, without the inclusion of diverse populations, such interventions may not be broadly generalizable. To help guide recruitment efforts, it is important to understand what factors are associated with patients' interest in participating in various forms of medical research. Some aspects of the research itself (e.g., time commitment, study procedures, and/or topic of investigation) affect interest in research participation. ${ }^{1-3}$ Additionally, sociodemographic factors such as age, race, gender, education, and income can play a role. ${ }^{4-8}$ However, little is known about the influence of health literacy and numeracy skills on interest in research participation.

Approximately one-third of adult Americans have limited health literacy or numeracy skills. ${ }^{9}$ Health literacy is "the degree to which individuals have the capacity to obtain, process, and understand basic health information and services needed to make appropriate health decisions."10, 11 Numeracy is "the ability to understand and use numbers in daily life." 12 Both health literacy and numeracy affect patients' understanding and management of their medical conditions, as well as decision-making preferences. ${ }^{13,14}$ In the research setting, we have previously demonstrated that health literacy is an important predictor of consent comprehension ${ }^{15}$ and study followup. ${ }^{16}$ Only one small analysis has linked health literacy to research participation, finding unexpectedly that patients who incorrectly interpreted a medication label were more likely to participate in a behavioral intervention study. ${ }^{2}$ The association of health literacy and numeracy with research participation interest across various types of research has not been 
examined, nor have health literacy and numeracy been evaluated together to establish their relative contributions.

Due to the high prevalence of limited health literacy and numeracy skills, it is important for researchers to understand the roles of health literacy and numeracy, and to tailor research recruitment strategies appropriately, particularly as the growing prominence of learning health systems may expand research opportunities in routine care. ${ }^{17}$ We examined the independent association of patients' health literacy and numeracy with their interest to participate in various types of research in a large pooled sample of adults.

\section{METHODS}

\section{Setting and Population}

The Mid-South Clinical Data Research Network (CDRN) is a collaboration focused on improving population health. ${ }^{18}$ At the time of this study, it included the Vanderbilt Health System, Vanderbilt Health Affiliated Network, Meharry Medical College, and Greenway Health. The present analysis uses pooled data from adult participants who enrolled in one of the following Mid-South CDRN studies: Coronary Heart Disease, Healthy Weight, or Stakeholder Engagement. ${ }^{19}$

The Coronary Heart Disease team surveyed adult patients identified through a validated claims-based algorithm for coronary heart disease. ${ }^{20}$ Recruitment focused on patients who received care in the cardiology clinics at Vanderbilt University Medical Center (VUMC) or affiliated sites, and had clinical contact with VUMC within the past 2 years. Surveys were administered via in-clinic contact, mail, telephone calls, or email through My Research at Vanderbilt, an opt-in research portal.

The Healthy Weight team recruited from 7 VUMC internal medicine clinics, an affiliated clinic in middle Tennessee, and 7 national clinics that are part of the Greenway Health network. Participants were eligible if they had at least 2 weight and 1 height measurements in their medical chart after April 30, 2009. Enrollment methods included electronic outreach through My Research at Vanderbilt, ResearchMatch (an online research registry), ${ }^{21}$ or direct email, as well as in-clinic recruitment.

The Stakeholder Engagement team recruited a diverse sample to understand attitudes towards research, identify barriers to participating in research, and determine research priorities for the network. The team administered surveys electronically using ResearchMatch and My Research at Vanderbilt and inperson to community members in local clinical and nonclinical community settings.

\section{Study Design}

All three studies were cross-sectional. Each study's design and conduct was informed by community members and patients using Community Engagement Studios. ${ }^{22}$ Each of the surveys was designed to be administered to a large sample while minimizing burden to respondents and to the setting, and thus, preference was given to short validated measures when available. Survey responses were collected using Research Electronic Data Capture (REDCap), ${ }^{23}$ a secure, web-based application. The Vanderbilt Institutional Review Board (IRB) approved each study. Participants provided electronic or written informed consent.

Data Availability. The datasets analyzed during the current study are available from the corresponding author on reasonable request.

\section{Data Collection}

Although each survey had distinct domains, they shared certain common elements-demographics (age, race/ethnicity, gender, income, marital status, household size, employment status, and education), health literacy, numeracy, prior research participation, and interest in participating in future research-which were pooled for this analysis.

Health literacy was assessed using the validated 3-item Brief Health Literacy Screen (BHLS), which significantly correlates with objective measures of health literacy and has demonstrated predictive validity in other studies. ${ }^{2-26}$ Each question has 5 response options and the responses are summed to get a final health literacy score of 3-15, with higher scores indicating higher health literacy. The questions are as follows: "How confident are you filling out medical forms by yourself?", "How often do you have someone help you read hospital materials?", and "How often do you have problems learning about your medical condition because of difficulty understanding written information?"

Numeracy was measured using a validated 3-item version of the Subjective Numeracy Scale (SNS-3), ${ }^{27}$ which is a shortened version of the full Subjective Numeracy Scale (SNS). ${ }^{28}$ The SNS-3 is significantly associated with an objective measure of numeracy, the Wide Range Achievement Test. ${ }^{27}$ The SNS-3 asks patients to self-report their ability to work with fractions, calculate the final purchase price of an item with a $25 \%$ discount, and how often they find numerical information useful. Responses range from 1 to 6, with higher numbers representing higher confidence, and are added for a score of 3-18. The Stakeholder Engagement survey used the same SNS-3 questions but with 1 to 5 response options, which were transformed for data pooling in the following manner: $1=1,2=2.25,3=3.5,4=4.75$, and $5=6$.

Interest in research participation was evaluated with a 7item questionnaire developed by a PCORnet task force. ${ }^{29}$ It ask about various types of research, ranging from survey completion to overnight hospitalization (see Table 2 for full questionnaire and Appendix for additional information about its development). The 3-item response scale ranges from 1 ("not interested") to 3 ("very interested"). Adding the 
responses together created an index from 7 to 21 , where higher scores indicate more interest in research participation. We calculated Cronbach's alpha to assess the level of internal consistency of the new index and performed a principal components factor analysis.

\section{Data Analysis}

Data were cleaned and analyzed using Stata, version 13.1 (StataCorp LP, College Station TX) and SPSS version 23.0 (IMB Corp, Armonk, NY). Because patients may have participated in more than one of the surveys, duplicate records were identified and removed, keeping each participant's first completed survey. Surveys that were missing a response to one or more of the research participation items (the study outcome) were excluded from analysis.

Frequency and descriptive statistics including mean with standard deviation (SD) and median with interquartile range (IQR) were calculated. Unadjusted and adjusted linear regression models examined associations between the interest in Research Participation Index and the following predictors: health literacy, subjective numeracy, age, race, household density, previous participation in research, gender, education, income, employment status, and marital status. Multiple imputation using Monte Carlo techniques was used to account for missing responses in covariates. We also performed a secondary analysis using unadjusted linear regression to examine the association of individual items in the Research Participation Index with the two predictors of greatest interest, health literacy and subjective numeracy. A two-tailed $p$ value $<0.05$ was considered statistically significant.

\section{RESULTS}

The response rate for the different surveys was $16.2 \%$ for Healthy Weight, $45.7 \%$ for Coronary Heart Disease, and $42.7 \%$ for Stakeholder Engagement. The pooled sample from all three groups included 19,098 records; of those, 1253 records were identified from individuals participating in more than one survey and were removed. Of the 17,845 unique participants, 1872 did not answer all 7 Research Participation Index items and were therefore excluded from analyses. Thus, the final analytical sample included 15,973 participants (Fig. 1).

Participants $(N=15,973)$ were predominately women $(65.5 \%)$, White $(81.4 \%)$, and middle aged $(M=52.8$ years, $\mathrm{SD}=16.5) ; 32.4 \%$ had previously participated in research (Table 1). About $25 \%$ reported earning less than $\$ 35,000$ per year, the average household size was about 2.4 people $(\mathrm{SD}=1.2)$, and over $50 \%$ reported attaining at least a college degree. Self-reported health literacy skills were relatively high $(M=13.5$ out of $15, \mathrm{SD}=2.1)$; subjective numeracy skills were lower relative to the scale's maximum score $(M=14.3$ out of $18, \mathrm{SD}=3.6)$.
When asked about interest in participating in specific kinds of research, many respondents indicated being "very interested" in research that involves completing surveys $(53.3 \%)$, participating via phone or internet $(40.0 \%)$, or giving a blood sample (37.2\%) (Table 2). People were less interested in research that involves taking a medication ( $14.5 \%$ very interested), meeting in a community center or school (15.8\%), including family members $(16.5 \%)$, or staying overnight in a hospital (12.1\%). The composite score on the 7-item interest in Research Participation Index ranged from 7 to $21 \quad(M=$ 13.8, $\mathrm{SD}=3.6$ ) and followed a normal distribution. The index demonstrated high internal consistency reliability (Cronbach's alpha $=0.86)$ and a single-factor solution (results not shown).

In unadjusted analyses (Table 3), higher health literacy, higher numeracy, younger age, and previous research experience were each significantly associated with greater interest in research participation $(p<0.001$ for each). Relative to non-Hispanic Whites, Hispanics indicated greater interest in research participation $(p<0.05)$, while interest was lower among Asian $(p<0.05)$ and multi-racial $(p<0.001)$ groups; no significant difference was observed between non-Hispanic Whites and Blacks. Compared to those with more than a college degree, there was significantly lower interest in research participation among people who had a high school degree or less $(p<0.001)$; however, those with some college had higher interest $(p<0.001)$. In most income brackets less than $\$ 100,000$, there was also more interest in research participation relative to those making more than $\$ 100,000(p<0.05$ or $p<0.001)$. Compared to those who were employed, those who were unemployed or disabled $(p<0.001)$ had more research participation interest while those who were retired had less interest $(p<0.001)$. Compared to those who were married, those who were divorced or separated were more interested in research participation $(p<0.001)$ while those who were widowed were less interested $(p<0.001)$. Household density and gender were not associated with interest in participating in research.

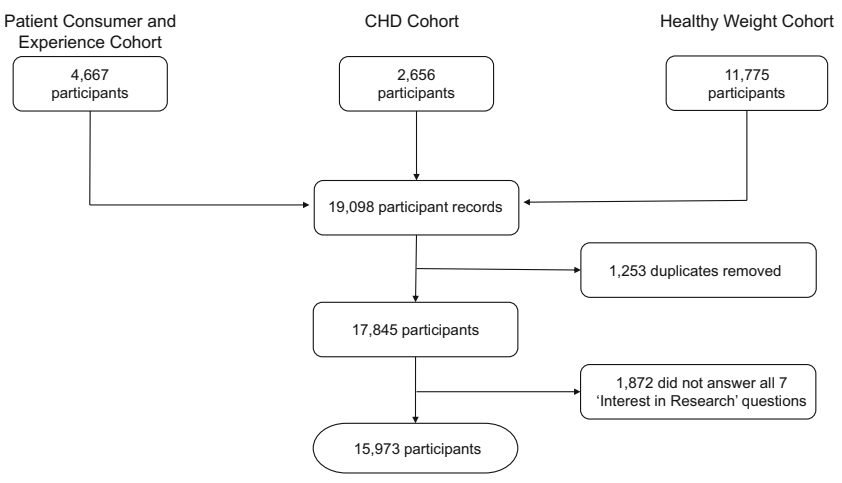

Figure 1 Study flow diagram. 
Table 1 Patient Characteristics $(N=15,973)$

\begin{tabular}{|c|c|}
\hline Research Participation Index, mean (SD) & $13.7(3.6)$ \\
\hline Health literacy (BHLS), mean (SD) & $13.5(2.1)$ \\
\hline Subjective numeracy (SNS), mean (SD) & $14.3(3.6)$ \\
\hline Age, mean (SD) & $52.8(16.5)$ \\
\hline Household density, mean (SD) & $2.4(1.2)$ \\
\hline \multicolumn{2}{|l|}{ Participated in research previously, $n(\%)$} \\
\hline Yes & $4823(32.4)$ \\
\hline No & $10,057(67.6)$ \\
\hline \multicolumn{2}{|l|}{ Gender, $n(\%)$} \\
\hline Female & $10,199(65.5)$ \\
\hline Male & $5380(34.5)$ \\
\hline \multicolumn{2}{|l|}{ Race/ethnicity, $n(\%)$} \\
\hline White (non-Hispanic) & $12,827(81.4)$ \\
\hline Black (non-Hispanic) & $1675(10.6)$ \\
\hline Hispanic & $286(1.8)$ \\
\hline Native American & $243(1.5)$ \\
\hline Asian & $248(1.6)$ \\
\hline Other & $65(0.4)$ \\
\hline Multi-racial & $424(2.7)$ \\
\hline \multicolumn{2}{|l|}{ Education, $n(\%)$} \\
\hline Less than high school & $489(3.1)$ \\
\hline High school degree & $2213(14.2)$ \\
\hline Some college/2-year degree & $4448(28.6)$ \\
\hline College degree & $3898(25.1)$ \\
\hline More than a college degree & $4512(29.0)$ \\
\hline \multicolumn{2}{|l|}{ Income, $n(\%)$} \\
\hline Less than $\$ 10,000$ & $631(4.5)$ \\
\hline$\$ 10,000$ to $\$ 19,999$ & $1081(7.7)$ \\
\hline$\$ 20,000$ to $\$ 34,999$ & $1904(13.6)$ \\
\hline$\$ 35,000$ to $\$ 49,999$ & $2032(14.5)$ \\
\hline$\$ 50,000$ to $\$ 74,999$ & $2883(20.5)$ \\
\hline$\$ 75,000$ to $\$ 99,999$ & $2139(15.2)$ \\
\hline$\$ 100,000$ or more & $3376(24.0)$ \\
\hline \multicolumn{2}{|l|}{ Employment, $n(\%)$} \\
\hline Employed & 8907 (55.9) \\
\hline Unemployed & $767(4.8)$ \\
\hline Retired & $3528(22.1)$ \\
\hline Unable to work (disabled) & $1394(8.8)$ \\
\hline $\begin{array}{l}\text { Other (homemaker, stay-at-home caregiver, } \\
\text { student, etc.) }\end{array}$ & $1333(8.4)$ \\
\hline \multicolumn{2}{|l|}{ Marital status, $n(\%)$} \\
\hline Married/living with partner & $10,938(69.0)$ \\
\hline Widowed & $860(5.4)$ \\
\hline Divorced/separated & $1986(12.5)$ \\
\hline Never married & $2075(13.1)$ \\
\hline
\end{tabular}

Missing counts for health literacy $=256$; subjective numeracy $=282$; age $=330 ;$, household density $=134$; participated in previous research $=$ 1093; gender 394; race $=372 ;$ education $=413 ;$ income $=1927$; employment $=44 ;$ and marital status $=114$

In adjusted analyses (Table 3), higher health literacy $(p<0.001)$, higher numeracy $(p<0.001)$, younger age $(p<0.05)$, and prior research experience $(p<0.001)$ remained independently associated with more interest in research participation. Asians were less interested in re- search compared to non-Hispanic Whites $(p<0.05)$. Compared to people with more than a college degree, research interest was lower among those with only a high school degree $(p<0.05)$, but significantly higher among people with some college but no degree $(p<0.001)$. Relative to those with income of $\$ 100,000$ or more, all lower income brackets expressed greater interest in research participation, with the greatest interest observed among the lowest income groups. Those who were unemployed or had disabled status had greater interest than those who were employed $(p<0.001)$. Finally, compared to married respondents, those who were divorced/ separated had greater interest, and those who were widowed or never married had less interest in research $(p<0.05)$.

In a secondary analysis, health literacy and numeracy were individually associated with 6 of 7 items in the Research Participation Index $(p<0.001$ for each comparison, see Appendix Table 4). For studies that would involve completion of surveys or communicating by phone or internet, health literacy and numeracy were strongly associated with participation interest. For studies involving less communication (e.g., giving blood or taking a medication) a weaker, but still significant, association with health literacy and numeracy was present.

\section{DISCUSSION}

In this large pooled sample study, we found that health literacy and numeracy were each independently associated with people's interest in participating in future research studies. Health literacy and numeracy retained a predictive relationship with research interest even in models adjusted for age, race, education, and income (factors known to predict research interest). To our knowledge, this is the largest investigation to date in this area, as well as the first study to examine both health literacy and numeracy in this context.

There are several possible explanations for these findings. Because patients with low health literacy or numeracy have greater difficulty understanding health-related information, they may be apprehensive about understanding expectations

Table 2 Interest in Research Participation by Type of Research Study $(N=15,973)$

\begin{tabular}{|c|c|c|c|}
\hline & Not interested & Somewhat interested & Very interested \\
\hline Completing a survey two or more times & $1135(7.1)$ & $6318(39.6)$ & $8520(53.3)$ \\
\hline Giving a blood sample & $2861(17.9)$ & $7169(44.9)$ & $5943(37.2)$ \\
\hline $\begin{array}{l}\text { Taking part in a study that involves talking by phone or is over the } \\
\text { internet (for example, to get advice about your health) }\end{array}$ & $2608(16.3)$ & $6976(43.7)$ & $6389(40.0)$ \\
\hline Taking part in a study where you have to take medication & $6903(43.2)$ & $6752(42.3)$ & $2318(14.5)$ \\
\hline Taking part in a study that involves meeting at a local community center or school & $6580(41.2)$ & $6873(43.0)$ & $2520(15.8)$ \\
\hline Taking part in a study that involves you and other people in your family & $6068(38.0)$ & $7262(45.5)$ & $2643(16.5)$ \\
\hline Taking part in a study where you would stay in the hospital for 1 or more days & $8065(50.5)$ & $5975(37.4)$ & $1933(12.1)$ \\
\hline
\end{tabular}

Values represent $N(\%)$ 
Table 3 Predictors of Interest in Research Participation

\begin{tabular}{|c|c|c|}
\hline & Unadjusted $^{\dagger}$ & Adjusted \\
\hline Health literacy (BHLS) & $.197(.172, .223)^{* *}$ & $.139(.109, .170)^{* *}$ \\
\hline Subjective numeracy (SNS) & $.106(.091, .121)^{* *}$ & $.106(.088, .124)^{* *}$ \\
\hline Age & $-.007(-.011,-.004)^{* *}$ & $-.005(-.010, .000)^{*}$ \\
\hline Household density & $.011(-.035, .056)$ & $.023(-.029, .075)$ \\
\hline \multicolumn{3}{|l|}{ Participated in research previously } \\
\hline Yes & $1.411(1.290,1.532)^{* *}$ & $1.195(1.070,1.320)^{* *}$ \\
\hline No (ref) & - & - \\
\hline \multicolumn{3}{|l|}{ Gender } \\
\hline Female (ref) & - & - \\
\hline Male & $-.062(-.181, .057)$ & $.028(-.101, .157)$ \\
\hline \multicolumn{3}{|l|}{ Race/ethnicity } \\
\hline White (non-Hispanic) (ref) & - & - \\
\hline Black (non-Hispanic) & $-.076(-.259, .107)$ & $-.106(-.299, .086)$ \\
\hline Hispanic & $.566(.146, .987) *$ & $.343(-.073, .759)$ \\
\hline Native American & $.262(-.194, .718)$ & $.305(-.140, .749)$ \\
\hline Asian & $-.783(-1.235,-.332)^{*}$ & $-.729(-1.172,-.285)^{*}$ \\
\hline Other & $-.377(-1.252, .499)$ & $-.092(-.954, .770)$ \\
\hline Multi-racial & $-1.204(-1.551,-.856)^{* *}$ & $-.334(-.856,0.188)$ \\
\hline \multicolumn{3}{|l|}{ Education } \\
\hline Less than high school & $-1.159(-1.493,-.825)^{* *}$ & $-.317(-.691, .058)$ \\
\hline High school degree & $-.668(-.850,-.486) * *$ & $-.235(-.443,-.028)^{*}$ \\
\hline Some college/2-year degree & $.282(.134, .430)^{* *}$ & $.401(.243, .560)^{* *}$ \\
\hline College degree & $-.069(-.223, .084)$ & $.050(-.104, .205)$ \\
\hline More than a college degree (ref) & - & - \\
\hline \multicolumn{3}{|l|}{ Income } \\
\hline Less than $\$ 10,000$ & $.300(-.004, .604)$ & $.716(.363,1.068)^{* *}$ \\
\hline$\$ 10,000$ to $\$ 19,999$ & $.635(.390, .880)^{* *}$ & $.813(.523,1.103)^{* *}$ \\
\hline$\$ 20,000$ to $\$ 34,999$ & $.341(.140, .542)^{*}$ & $.617(.395, .839)^{* *}$ \\
\hline$\$ 35,000$ to $\$ 49,999$ & $.296(.099, .493)^{*}$ & $.515(.313, .716)^{* *}$ \\
\hline$\$ 50,000$ to $\$ 74,999$ & $.203(.025, .381)^{*}$ & $.340(.158, .521)^{* *}$ \\
\hline$\$ 75,000$ to $\$ 99,999$ & $.201(.007, .395) *$ & $.265(.062, .468) *$ \\
\hline$\$ 100,000$ or more (ref) & - & - \\
\hline \multicolumn{3}{|l|}{ Employment } \\
\hline Employed (ref) & - & - \\
\hline Unemployed & $1.119(.855,1.384) * *$ & $1.080(.793,1.366) * *$ \\
\hline Retired & $-.364(-.503,-.224) * *$ & $-.114(-.293, .065)$ \\
\hline Unable to work (disabled) & $.650(.448, .853)^{* *}$ & $.961(.734,1.188)^{* *}$ \\
\hline Other (homemaker, stay-at-home & $-.174(-.380, .032)$ & $-.209(-.422, .005)$ \\
\hline caregiver, student, etc.) & & \\
\hline \multicolumn{3}{|l|}{ Marital status } \\
\hline Married/living with partner (ref) & - & - \\
\hline Divorced/separated & $.556(.384, .728)^{* *}$ & $.300(.110, .490)^{*}$ \\
\hline Widowed & $-.515(-.765,-.266)^{* *}$ & $-.352(-.621,-.083)^{*}$ \\
\hline Never married & $-.007(-.176, .161)$ & $-.262(-.462,-.062) *$ \\
\hline
\end{tabular}

Values represent $\beta(95 \%$ CI)

$* p<0.05 ; * * p<0.001$

+ Missing counts in unadjusted analysis for health literacy = 256; subjective numeracy = 282; age = 330; household density = 144; participated in previous research $=1093$; gender 394; race $=205$; education $=413 ;$ income $=1927$; employment $=44 ;$ and marital status $=114$

and risks of research. Indeed, prior research has shown that patients with low health literacy have greater difficulty understanding informed consent for research studies, even when information is presented orally and other steps are taken to simplify the process, such as use of visual aids and teachback. ${ }^{15,}{ }^{30}$ Further, patients with lower health literacy or numeracy skills may avoid situations which would require use of these skills. Our study found some evidence to support this in secondary analyses which showed that interest in forms of research with greater communication-related demands (e.g., surveys, engaging with health advice via phone or internet) had the strongest associations with health literacy and numeracy. Similar to previous studies, ${ }^{31}$ our results also indicated that health literacy and numeracy maintained distinct effects on research participation interest. While health literacy encompasses an individual's ability to obtain, understand, and act on health information, health numeracy is a specific aspect of health literacy that involves an individual's interactional ability with quantitative information. ${ }^{32,}{ }^{33}$ In the context of research participation, health literacy may relate to understanding the research topic and general requirements for participation, while numeracy may involve one's ability to quantify the risks and benefits of participation as well as problem solving participation alternatives.

Interestingly, we found that, even after adjustment for educational attainment, individuals with lower household income were more interested in participating in research, along with those who were either unemployed or unable to work/disabled. Previous studies have generally not shown this relationship, ${ }^{34}$ though in one recent study, parents of young children with an annual household income of $\$ 25,000-\$ 50,000$ were more likely to indicate willingness 
Table 4 Unadjusted Associations of Interest in Research Participation with Health Literacy and Subjective Numeracy

\begin{tabular}{|c|c|c|}
\hline & $\begin{array}{l}\text { Health literacy } \\
\text { (BHLS) } \\
n=15,717\end{array}$ & $\begin{array}{l}\text { Subjective } \\
\text { numeracy } \\
\text { (SNS) } \\
n=15,691\end{array}$ \\
\hline $\begin{array}{l}\text { Completing a survey two } \\
\text { or more times }\end{array}$ & $.058(.054, .063)^{* *}$ & $.027(.025, .030)^{* *}$ \\
\hline Giving a blood sample & $.038(.033, .043) * *$ & $.022(.019, .025) * *$ \\
\hline $\begin{array}{l}\text { Taking part in a study that } \\
\text { involves talking by phone } \\
\text { or is over the internet } \\
\text { (for example, to get } \\
\text { advice about your health) }\end{array}$ & $.051(.046, .056)^{* *}$ & $.025(.022, .028) * *$ \\
\hline $\begin{array}{l}\text { Taking part in a study } \\
\text { where you have to take } \\
\text { medication }\end{array}$ & $.014(.009, .019)^{* *}$ & $.009(.006, .012)^{* * *}$ \\
\hline $\begin{array}{l}\text { Taking part in a study } \\
\text { that involves meeting at } \\
\text { a local community } \\
\text { center or school }\end{array}$ & $.021(.016, .026)^{* *}$ & $.010(.007, .013)^{* * *}$ \\
\hline $\begin{array}{l}\text { Taking part in a study } \\
\text { that involves you and } \\
\text { other people in your } \\
\text { family }\end{array}$ & $.014(.009, .019)^{* *}$ & $.014(.011, .017)^{* *}$ \\
\hline $\begin{array}{l}\text { Taking part in a study } \\
\text { where you would stay } \\
\text { in the hospital for } 1 \text { or } \\
\text { more days }\end{array}$ & $.001(-.004, .006)$ & $.000(-.003, .003)$ \\
\hline
\end{tabular}

Values represent $\beta(95 \%$ CI)

$*_{p}<0.05 ; * * p<0.001$

to participate than parents with an annual household income of more than $\$ 75,000 . .^{35}$ Our findings suggest that individuals from lower socioeconomic strata may be willing to participate, and researchers should continue to pursue recruitment from these traditionally underserved populations. Indeed, there is some evidence that the financial remuneration opportunities available through clinical research may make participation more attractive to patients with lower socioeconomic status (SES). However, community feedback is necessary to ensure financial incentives are not excessive to unduly influence participation. ${ }^{36}$

Previous studies have shown that African Americans, Latinos, and Asians are less likely to participate in research. $^{37}$ In one study of an urban African American population, this was attributed to a lack of perceived trust with medical institutions. ${ }^{34}$ However, we did not observe less interest in research among African Americans and Latinos in adjusted analyses. The most likely explanations are that our sample had a relatively high level of educational attainment, and our data necessarily came only from individuals who had agreed to participate in a survey. Thus, they had already crossed a threshold to participate in research. Such individuals may have lower levels of mistrust and more altruistic views on research, and thus demonstrated no difference when compared to White participants in their interest to participate in future research studies.

Strengths of the present study include subject recruitment from diverse sites, including academic medical clinics, communitybased practices, community health centers, and non-clinical community settings. This resulted in a large population, with different levels of experience and exposure to research.

Several limitations were present. First, the outcome represents a self-reported interest in research participation, rather than actual participation. Assessing willingness permitted a larger and more efficient exploration of the subject, but it is unclear whether the findings would translate to actual research participation. Second, as noted above, the data are from individuals who had already consented to participate in a survey. Thus, the findings are subject to selection bias and may not generalize to research-naïve populations. Third, owing largely to the greater use of electronic recruitment strategies, the enrollment rate was lower for the Healthy Weight cohort compared to that of the cohorts for Coronary Heart Disease and Stakeholder Engagement. An evaluation of non-response bias using inverse probability weighting indicated the sociodemographics of each study were similar, and the composition of the overall recruited population and the population seeking care across the MidSouth CDRN were also similar. ${ }^{19}$ Fourth, while our study sample was reflective of the patients who seek care as part of the Mid-South CDRN, our sample was mostly White, very few were unemployed, most had at least some college, and subjective health literacy and numeracy were high. This may limit generalization of our findings to broader populations. Nonetheless, health literacy and numeracy continued to be independently associated with willingness to participate in research in this sample even after adjustment for ethnicity/race and socioeconomic factors. Additional research is needed to understand if this association persists (or may be even stronger) among those with lower literacy and numeracy and in more ethnically, racially, and socioeconomically diverse groups. Finally, we used validated subjective measures of health literacy and numeracy for their efficiency in this large population-based study. Subjective measures may over-predict actual skill levels, and the estimates of observed effect would likely differ somewhat if different measures were selected.

Recruitment of diverse populations in research is of critical importance to enhance the generalizability of findings and applicability to at-risk populations. We demonstrated that adults with low health literacy or numeracy are significantly less interested in participating in research. These factors are more prevalent among racial and ethnic minorities and individuals with lower SES. Efforts to make research more accessible to all populations via effective health communication may increase interest in research participation among minorities and low SES groups. ${ }^{38}$ For example, in-person recruitment, verbal instructions, and verbal completion of questionnaires may increase willingness to participate. When in-person and/or verbal interactions are not feasible, additional attention to the grade level of written materials along with their suitability may foster potential participant understanding of the research and thereby increase interest. Researchers who engage low health literacy and numeracy participants should remain attentive to effective health communication throughout the research process (i.e., from recruitment and informed 
consent to in-study communication and dissemination of results). Such attention will help ensure all participants have the opportunity to understand, interact with, and benefit from research, thereby increasing future research interest in the study participants and their communities.

Corresponding Author: Sunil Kripalani, MD, MSc; Center for Clinical Quality and Implementation Research Vanderbilt University Medical Center, Nashville, TN, USA (e-mail: sunil.kripalani@vumc.org).

Contributors There are no additional contributors to this manuscript.

Funders This work was supported by the Patient-Centered Outcomes Research Institute (R-1306-04869 and ME-1306-03342) and the National Institutes of Health (5UL1TR000445, 5U54MD007593, and 5U24TR001579).

\section{Compliance with Ethical Standards:}

The Vanderbilt Institutional Review Board (IRB) approved each study. Participants provided electronic or written informed consent.

Prior Presentations: Patel, N.J., Jackson, N., Duke, L., Wilkins, C.H., Heerman, W.J., and Kripalani, S. The Effect of Health Literacy and Numeracy on Interest in Research Participation. Presented at the Advancing the Science of Community Engaged Research Conference in 2016.

Conflict of Interest: Sunil Kripalani, MD, MSc - Consultancies: SAI Interactive and Verustat/Stock ownership in Bioscape Digital.

Russell L. Rothman, MD, MPP - Consultancies: EdLogics, Inc. and Boehringer - Ingelheim.

Kenneth A. Wallston, PhD - Other - Member of the Advisory Board of EdLogics, Inc.

All other authors declare no conflicts of interest.

Publisher's note: Springer Nature remains neutral with regard to jurisdictional claims in published maps and institutional affiliations.

\section{REFERENCES}

1. Taylor RG, Hounchell M, Ho M, Grupp-Phelan J. Factors associated with participation in research conducted in a pediatric emergency department. Pediatr Emerg Care. 2015;31:348-52.

2. Voss R, Gravenstein S, Baier R, et al. Recruiting hospitalized patients for research: how do participants differ from eligible nonparticipants? J Hosp Med. 2013;8:208-14. https://doi.org/10.1002/jhm.2024

3. Bonevski B, Randell M, Paul C, et al. Reaching the hard-to-reach: a systematic review of strategies for improving health and medical research with socially disadvantaged groups. BMC Med Res Methodol. 2014;14:1.

4. George S, Duran N, Norris $\mathbf{K}$. A systematic review of barriers and facilitators to minority research participation among African Americans, Latinos, Asian Americans, and Pacific Islanders. Am J Public Health. 2014; 104:e16-e31.

5. Scharff DP, Mathews KJ, Jackson P, Hoffsuemmer J, Martin E, Edwards D. More than Tuskegee: understanding mistrust about research participation. J Health Care Poor Underserved. 2010;2 1:879.

6. Steinerman J, Lipton R, Rapkin B, Guaranto B, Schwartz C. Factors associated with openness to research participation in an aging community: The importance of technophilia and social cohesion. Gerontechnology. 2013;11:504-12.

7. Unger JM, Hershman DL, Albain KS, et al. Patient income level and cancer clinical trial participation. J Clin Oncol. 2013;31:536-42.

8. Stewart JH, Bertoni AG, Staten JL, Levine EA, Gross CP. Participation in surgical oncology clinical trials: gender-, race/ethnicity-, and agebased disparities. Ann Surg Oncol. 2007;14:3328-34.

9. Kutner MA, Greenberg E, Baer J. National Assessment of Adult Literacy (NAAL): A first look at the literacy of America's adults in the 21st century. US Department of Education. Washington, DC: National Center for Education Statistics; 2005.
10. Institute of Medicine Committee on Health Literacy. Health Literacy: A Prescription to End Confusion. Washington (DC): National Academies Press; 2004.

11. Ratzan SC, Parker, RM, Selden CR, Zorn, CR. National library of medicine current bibliographies in medicine: Health Lliteracy. Bethesda (MD): U.S. Department of Health and Human Services, National Institues of Health; 2000.

12. Rothman RL, Housam R, Weiss $\mathbf{H}$, et al. Patient understanding of food labels: the role of literacy and numeracy. Am J Prev Med. 2006;31:391-8.

13. DeWalt DA, Berkman ND, Sheridan S, Lohr KN, Pignone MP. Literacy and health outcomes. J Gen Intern Med. 2004;19:1228-39.

14. Goggins KM, Wallston KA, Nwosu S, et al. Health literacy, numeracy, and other characteristics associated with hospitalized patients' preferences for involvement in decision making. J Health Commun. 2014;19:29-43.

15. Kripalani S, Bengtzen R, Henderson LE, Jacobson TA. Clinical research in low-literacy populations: using teach-back to assess comprehension of informed consent and privacy information. IRB. 2008;30:13-9.

16. Leak C, Goggins $\mathbf{K}$, Schildcrout JS, et al. Effect of health literacy on research follow-up. J Health Commun. 2015;20:83-91.

17. Greene SM, Reid RJ, Larson EB. Implementing the learning health system: from concept to action. Ann Intern Med. 2012;157:207-10.

18. Rosenbloom ST, Harris P, Pulley $\mathbf{J}$, et al. The Mid-South Clinical Data Research Network. J Am Med Inform Assoc. 2014;21:627-32.

19. Heerman WJ, Jackson N, Roumie CL, et al. Recruitment methods for survey research: findings from the Mid-South Clinical Data Research Network. Contemp Clin Trials. 2017;62:50-5.

20. Roumie CL, Shirey-Rice J, Kripalani S. MidSouth CDRN - coronary heart disease algorithm. PheKB. 2014. https://phekb.org/phenotype/ 234.

21. Harris PA, Scott KW, Lebo L, Hassan N, Lighter C, Pulley J. ResearchMatch: a national registry to recruit volunteers for clinical research. Acad Med. 2012;87:66.

22. Joosten YA, Israel TL, Williams NA, et al. Community engagement studios: a structured approach to obtaining meaningful input from stakeholders to inform research. Acad Med. 2015;90: 1646.

23. Harris PA, Taylor $\mathbf{R}$, Thielke $\mathbf{R}$, Payne $\mathbf{J}$, Gonzalez N, Conde JG. Research Electronic Data CAPture (REDCap) - A metadata-driven methodology and workflow process for providing translational research informatics support. Biomed Inform. 2009;42:377-81.

24. McNaughton CD, Cawthon C, Kripalani S, Liu D, Storrow AB, Roumie CL. Health literacy and mortality: a cohort study of patients hospitalized for acute heart failure. J Am Heart Assoc. 2015;4:e001799.

25. McNaughton CD, Kripalani S, Cawthon C, Mion LC, Wallston KA. Roumie CL. Association of health literacy with elevated blood pressure: a cohort study of hospitalized patients. Med Care. 2014;52:346.

26. Wallston KA, Cawthon C, McNaughton CD, Rothman RL, Osborn CY, Kripalani S. Psychometric properties of the brief health literacy screen in clinical practice. J Gen Intern Med. 2014;29:119-26.

27. McNaughton CD, Cavanaugh KL, Kripalani S, Rothman RL, Wallston KA. Validation of a short, 3-item version of the Subjective Numeracy Scale. Med Decis Making. 2015;35:932-6.

28. Fagerlin A, Zikmund-Fisher BJ, Ubel PA, Jankovic A, Derry HA, Smith DM. Measuring numeracy without a math test: development of the Subjective Numeracy Scale. Med Decis Making. 2007;27:672-80.

29. Heerman WJ, Bennett WL, Kraschnewski JL, Nauman E, Staiano AE, Wallston KA. Willingness to participate in weight-related research as reported by patients in PCORnet clinical data research networks. BMC Obes. 2018;5:10.

30. Ownby RL, Acevedo A, Goodman K, Caballero J, Waldrop-Valverde $\mathbf{D}$. Health literacy predicts participant understanding of orally-presented informed consent information. Clin Res Trials. 2015; 1:15-9. https://doi. org/10.15761/CRT. 1000105

31. Cavanaugh $\mathbf{K}$, Huizinga MM, Wallston KA, et al. Association of numeracy and diabetes control. Ann Intern Med. 2008;148:737-46.

32. Baker DW. The meaning and the measure of health literacy. J Gen Intern Med. 2006;21:878-83.

33. Rothman RL, Montori VM, Cherrington A, Pignone MP. Perspective: the role of numeracy in health care. J Health Commun. 2008; 13:583-95.

34. Shavers VL, Lynch CF, Burmeister LF. Racial differences in factors that influence the willingness to participate in medical research studies. Ann Epidemiol. 2002;12:248-56.

35. Svensson K, Ramirez OF, Peres F, Barnett M, Claudio L. Socioeconomic determinants associated with willingness to participate in medical research among a diverse population. Contemp Clin Trials. 2012;33:1197-205 
36. UyBico SJ, Pavel S, Gross CP. Recruiting vulnerable populations into research: a systematic review of recruitment interventions. J Gen Intern Med. 2007;22:852-63.

37. George S, Duran N, Norris K. A systematic review of barriers and facilitators to minority research participation among African Americans, Latinos, Asian Americans, and Pacific Islanders. Am J Public Health. 2014;104:e16-31.

38. Hughson JA, Woodward-Kron R, Parker A, et al. A review of approaches to improve participation of culturally and linguistically diverse populations in clinical trials. Trials. 2016;17:263.

\section{APPENDIX}

\section{Development of the interest in research participation measure}

The 7-item measure of research participation interest was created by combining instruments that had been developed by the Mid-South CDRN and Greater Plains Collaborative CDRN. The instruments of these two CDRNs were developed by groups of experts in health behavior and health services research along with feedback from local patients and health care providers. These combined questions were then revised and refined based upon discussion among a SWAT Team that proposed standardized survey questions for administration by CDRNs for all planned PCORnet cohort studies 